\title{
SERPINB11 Expression Is Associated With Prognosis of High-grade Serous and Clear Cell Carcinoma of the Ovary
}

\author{
SOO JIN PARK ${ }^{1 *}$, WHASUN LIM ${ }^{2 *}$, JAEHEE MUN ${ }^{1}$, HAERIN PAIK $^{1}$, SUNWOO PARK $^{3}$, \\ HYUNJI LIM ${ }^{1}$, JUNHWAN KIM ${ }^{1}$, EUN JI LEE ${ }^{1}$, GA WON YIM ${ }^{4}$, NARA LEE ${ }^{5}$, CHEOL LEE ${ }^{6}$, \\ JAE-WEON KIM ${ }^{1}$, GWONHWA SONG ${ }^{3}$ and HEE SEUNG KIM ${ }^{1}$ \\ ${ }^{1}$ Department of Obstetrics and Gynecology, \\ Seoul National University College of Medicine, Seoul, Republic of Korea; \\ ${ }^{2}$ Department of Food and Nutrition, Kookmin University, Seoul, Republic of Korea; \\ ${ }^{3}$ Institute of Animal Molecular Biotechnology and Department of Biotechnology, \\ College of Life Sciences and Biotechnology, Korea University, Seoul, Republic of Korea; \\ ${ }^{4}$ Department of Obstetrics and Gynecology, Dongguk University Ilsan Hospital, Goyang, Republic of Korea; \\ ${ }^{5}$ Department of Obstetrics \& Gynecology, CHA Gangnam Medical Center, \\ CHA University, Seoul, Republic of Korea; \\ ${ }^{6}$ Department of Pathology, Seoul National University College of Medicine, Seoul, Republic of Korea
}

\begin{abstract}
Background/Aim: To evaluate the role of serine protease inhibitor B11 (SERPINB11) expression as a prognostic biomarker in high-grade serous carcinoma (HGSC) and clear cell carcinoma of the ovary (CCC). Materials and Methods: We obtained tumor tissues from patients with HGSC $(n=145)$ and CCC (n=59). We evaluated immunohistochemically the expression of SERPINB11 and investigated whether SERPINB11 expression affects platinum-resistance and the prognosis of HGSC and CCC. Results: High expression of SERPINB11 was more common in CCC than in HGSC $(57.6 \%$ vs. 28.3\%; $p<0.01)$, and SEPRINB11 expression did not correlate with platinum-resistance of HGSC and CCC. High expression of SERPINB11 was associated with worse progression-free survival and overall survival with marginal significance in HGSC; no relation between SERPINB11 expression and the prognosis of
\end{abstract}

This article is freely accessible online.

\footnotetext{
*These Authors contributed equally to this study.

Correspondence to: Gwonhwa Song, Ph.D., Department of Biotechnology, College of Life Sciences and Biotechnology, Korea University, Seoul, 02841, Republic of Korea. Tel: +82 232903012, Fax: +82 232904994, e-mail: ghsong@korea.ac.kr; Hee Seung Kim, MD, Ph.D., Department of Obstetrics and Gynecology, Seoul National University College of Medicine, 101 Daehak-Ro, JongnoGu, Seoul 03080, Republic of Korea. Tel: +82 220724863, Fax: +82 27623599, e-mail: bboddi0311@gmail.com
}

Key Words: High-grade serous, clear cell, ovarian cancer, SERPINB11, prognosis
CCC was found. Conclusion: SERPINB11 expression maybe a prognostic biomarker for HGSC.

Epithelial ovarian cancer (EOC) is the most fatal among female genital tract malignancies due to the lack of effective screening methods for detecting early-stage disease (1). Among all histologic types, high-grade serous carcinoma (HGSC) is the most common histologic type and consists of $80 \%$ of EOC, whereas endometrioid, mucinous, and clear cell carcinoma (CCC) comprise the $10 \%, 5 \%$, and $5 \%$ (2). Considering that histologic type is a well known prognostic factor for EOC (3), CCC reportedly showed the worst prognosis (4-6). Moreover, estrogen exposure is one of the well-known risk factors for EOC (7-9), and specific histologic types such as HGSC and CCC have been reported to be associated with prolonged exposure to estrogen $(9,10)$, suggesting that an imbalanced effect of estrogen could influence the tumorigenesis of HGSC and CCC $(11,12)$. On the other hand, the paradoxical finding that HGSC may show high levels of estrogen receptors, whereas CCC may show low levels of estrogen receptors has been suggested to be a prognostic factor affecting treatment response (13).

As a biomarker related to the hormone, serine protease inhibitors (serpins) belong to the family of protease inhibitors, and 36 types of serpins are known in humans, which are classified into nine clades (14). They are involved in various processes such as blood coagulation, angiogenesis, immune response, fibrinolysis, and most of them exist as secreted forms in plasma $(14,15)$. Clade B serpins (SERPINB) have no signal peptide, exist as cytoplasmic 


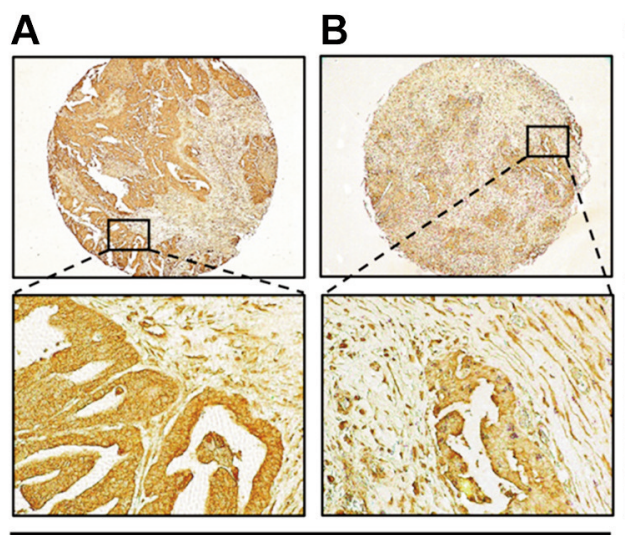

Serous carcinoma

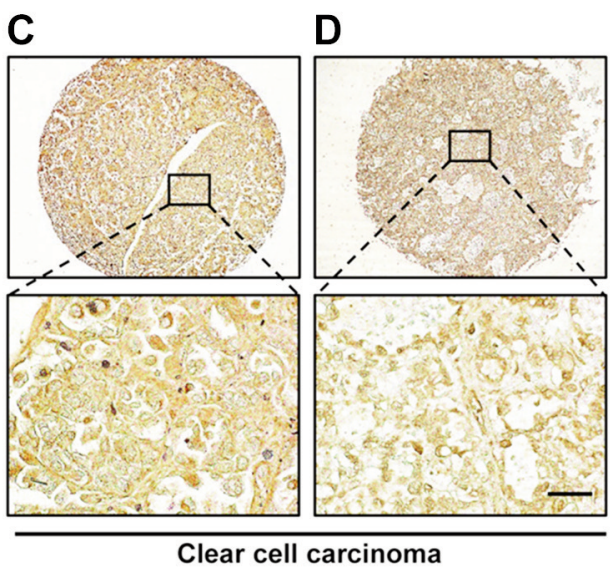

Figure 1. SERPINB11 expression in ovarian cancer tissues: (A) High and (B) low expression levels of SERPINB11 in high-grade serous carcinoma; (C) high and $(D)$ low expression levels of SERPINB11 in clear cell carcinoma of the ovary. The scale bar indicates 50 um.

proteins, and actthrough a non-inhibitory mechanism. Especially, SERPINB11 has been reported to show high expression in ovarian cancer lesions of hens and human ovarian cancer cell lines $(13,16)$. However, the prognostic role of SERPINB11 expression in EOC has not been elucidated. Previous studies on the effect of SERPINB 11 expression on ovarian differentiation and carcinogenesis have only been reported to the extent which the balance of diethylstilbestrol, as a synthetic estrogen, was essential in the development and maintenance of oviduct in the avian model $(17,18)$, and the increased expression of SERPINB11 in a chicken ovarian cancer model was associated with exposure of the chicken oviduct to diethylstilbestrol (19).

In this study, we compared the immunohistochemical expression of SERPINB11 between HGSC and CCC using tissue microarray and evaluated the role of SERPINB11 expression as a prognostic biomarker for predicting platinum-resistance and survival in patients with HGSC and $\mathrm{CCC}$, under the hypothesis that expression of SERPINB11 might be increased in human EOC tissues, and its pathogenesis might be associated with estrogen exposure.

\section{Materials and Methods}

We searched the data of patients with HGSC and CCC between July 2001 and November 2012 and obtained approval from the Institutional Review Board for the current study in advance (No. 1311-050-533). We included patients with the following criteria: those with HGSC or CCC; those who underwent cytoreductive surgery followed by adjuvant chemotherapy; those with an Eastern Cooperative Oncology Group performance status of 0-2; and those without underlying diseases affecting survival.

We collected the following data: the International Federation of Gynecology and Obstetrics (FIGO) stage, age, the extent of cytoreduction, platinum-resistance, progression-free survival (PFS), and overall survival (OS). In this study, we defined optimal cytoreduction as the maximal diameter of a residual tumor $<1 \mathrm{~cm}$, whereas suboptimal cytoreduction was defined as the maximal diameter of a residual tumor $\geq 1 \mathrm{~cm}$ after cytoreductive surgery. All patients received six cycles of adjuvant chemotherapy using paclitaxel $\left(175 \mathrm{mg} / \mathrm{m}^{2}\right)$ and carboplatin (AUC 5) every three weeks. Platinum-resistance was defined as a poor response to chemotherapy with a treatment-free interval of fewer than six months. PFS was defined as the time elapsed from the treatment start date to the date of disease recurrence, and OS was defined as the time from the treatment start date to the date of death or end of the study.

For immunohistochemistry, we took representative core tissue sections ( $2 \mathrm{~mm}$ diameter) from paraffin blocks and arranged them in new tissue microarray blocks using a trephine apparatus (SuperBioChips Laboratories, Seoul, Republic of Korea). Furthermore, expression of SERPINB11 was evaluated by immunohistochemistry using a primary antibody obtained from Santa Cruz Biotechnology (Santa Cruz, CA, USA), and the substitution of the primary antibody with purified non-immune mouse $\mathrm{IgG}$ was included at the same concentration for negative controls. Thereafter, one pathologist unaware of the clinicopathologic characteristics of patients interpreted the level of SERPINB11 expression semi-quantitatively based on the staining intensity (Intensity score; 1, weak; 2, moderate; 3, strong) and percentage of positive cells (Percentage score, $1,<25 \% ; 2,25-$ $50 \% ; 3,51-75 \% ; 4,>75 \%)$. The final immunoreactive score, which was calculated by the Intensity score multiplied by the Percentage score, ranging from 1 to 12 , and the high expression of the gene was considered when the final immunoreactive score was six or more.

For evaluating the role of SERPINB11 expression in platinumresistance, we used the Chi-square and Student's $t$-tests, and logistic regression analysis to determine the odds ratio $(\mathrm{OR})$ and $95 \%$ confidence interval (CI). For survival analysis, we used Kaplan-Meier analysis with the log-rank test and Cox proportional hazards analysis to estimate the hazard ratio (HR) and 95\%CI. Statistical analysis and calculations were performed using SPSS software version 21.0 (SPSS Inc., Chicago, IL, USA). In this study, $p$-value $<0.05$ indicated statistically significant differences. 
Table I. Clinicopathologic characteristics of patients with high-grade serous carcinoma (HGSC) and clear cell carcinoma (CCC) of the ovary.

\begin{tabular}{lccc}
\hline Characteristics & $\begin{array}{c}\text { HGSC } \\
(\mathrm{n}=145, \%)\end{array}$ & $\begin{array}{c}\text { CCC } \\
(\mathrm{n}=59, \%)\end{array}$ & $p$-Value \\
\hline Age (years) & & & 0.03 \\
$\quad \leq 52$ & $70(48.3)$ & $39(66.1)$ & \\
$>52$ & $75(51.7)$ & $20(33.9)$ & \\
FIGO stage & & & $<0.01$ \\
$\quad$ I-II & $10(6.9)$ & $39(66.1)$ & \\
$\quad$ III-IV & $135(93.1)$ & $20(33.9)$ & \\
Neoadjuvant chemotherapy & & 0.01 & \\
$\quad$ No & $126(86.9)$ & $58(98.3)$ & \\
$\quad$ Yes & $19(13.1)$ & $1(1.7)$ & \\
Residual tumor size (cm) & & & $<0.01$ \\
$\quad<1$ & $79(54.5)$ & $51(86.4)$ & \\
$\quad \geq 1$ & $66(45.5)$ & $8(13.6)$ & \\
Platinum-resistance & & & 0.35 \\
$\quad$ No & $34(23.4)$ & $49(83.1)$ & \\
$\quad$ Yes & $111(76.6)$ & $10(16.9)$ & \\
Response & & & 0.06 \\
Complete response & $107(73.9)$ & $52(88.1)$ & \\
Partial response & $26(17.9)$ & $2(3.4)$ & \\
Stable disease & $6(4.1)$ & $2(3.4)$ & \\
$\quad$ Progressive disease & $6(4.1)$ & $3(5.1)$ & \\
SERPINB11 expression & & & $<0.01$ \\
$\quad$ Low & $104(71.7)$ & $25(42.4)$ & \\
High & $41(28.3)$ & $34(57.6)$ & \\
\hline
\end{tabular}

FIGO: International Federation of Gynecology and Obstetrics.

\section{Results}

A total of 204 patients with HGSC $(n=145)$ and CCC $(n=59)$ were included in this study. Figure 1 shows low and high expression levels of SERPINB11, and Table I shows the clinicopathologic characteristics of all patients. Older age, stage III-IV disease, and the use of neoadjuvant chemotherapy were more common in patients with HGSC than in those with CCC, whereas optimal cytoreduction and high xpression of SERPINB11 were more frequent in those with CCC. Although the complete response rate was higher in patients with CCC with marginal significance, there was no difference in the frequency of platinum-resistance between HGSC and CCC patients.

Multivariate analyses showed that suboptimal cytoreduction was a factor associated with an increase in platinum-resistance in patients with HGSC (adjusted $\mathrm{OR}=3.469 ; 95 \% \mathrm{CI}=1.475-8.155 ; p<0.01)$, whereas stage I-II disease was related to a decrease in platinum-resistance in those with CCC (adjusted $\mathrm{OR}=0.126 ; 95 \% \mathrm{CI}=0.020-0.783$; $p=0.03$ ). However, high expression of SERPINB11 did not affect platinum-resistance in both HGSC and CCC patients (adjusted ORs $=0.623$ and $0.293 ; 95 \%$ Cis $=0.258-1.505$ and 0.175-4.833; tables not shown).
In patients with HGSC, high expression of SERPINB11 showed worse PFS (median, 16.5 vs. 22.4 mons; $p=0.052$ ) and OS (mean, 61.6 vs. 90.5 mons; $p=0.084$ ) with marginal significance. However, there were no differences in PFS and OS between low and high expression of SERPINB11 in patients with CCC (mean, $78.7 v s .100 .8$ mons, and 111.4 vs. 113.6 mons; $p>0.05$; Figure 2). In multivariate analyses, high expression of SERPINB11 was associated with poor PFS (adjusted $\mathrm{HR}=1.505 ; 95 \% \mathrm{CI}=0.982-2.306 ; p=0.06$ ) and $\mathrm{OS}$ (adjusted $\mathrm{HR}=1.697 ; 95 \% \mathrm{CI}=0.977-2.948 ; p=0.06$ ) with marginal significance in patients with HGSC (Table II). However, high expression levels of SERPINB11 were not associated with PFS and OS in those with CCC (adjusted $\mathrm{HRs}=0.844$ and 1.073 ; 95\%CIs=0.350-2.032 and 0.330$3.482 ; p>0.05$; Table III).

\section{Discussion}

Up to now, the roles of SERPINB2, SERPINB3, SERPINB4, and SERPINB5 among the different subtypes of SERPINB have been elucidated in cancer cells. SERPINB2, which is the first known urokinase-type plasminogen activator, has been shown to have a role in the progression and metastasis of head and neck, breast, and lung cancers (20-22). SERPINB3 and SERPINB4 are known to be co-expressed in healthy human tissues such as the tongue, tonsil, uterine cervix, and respiratory tract epithelium (23), whereas their transition to squamous cell carcinoma may induce the excretion of SERPINB3 and SERPINB4 (24). Moreover, SERPINB5, which is known as Maspin, is over-expressed and localized in ovarian cancer tissues, which may play an essential role in inducing angiogenesis for tumor progression $(25,26)$.

Especially, SERPINB has been reported to have an inhibitory action on proteins related to tumor invasions, such as extracellular matrix degradation in human breast and ovarian cancers (27). On the contrary, we showed that high expression of SERPINB11 may be associated with poor prognosis of HGSC, not CCC. We thought that an estrogendependent mechanism might be involved in the association between high expression of SERPINB11 and poor prognosis of ovarian cancer. Previous studies on serpins have demonstrated that SERPINA6 acts as a corticosteroid-binding globulin (28), and the conformational change of SERPINA6 attributes toit a corticosteroid transporter function (29). This means that serpins could affect hormone-dependent tumor growth and differentiation, which can be supported by our previous studies where the treatment of a chicken ovarian cancer model with estrogen showed significantly increased expression of SERPINBI1 in the oviducts (19).

Moreover, the effect of high expression of SERPINB11 on prognosis was observed only in patients with HGSC in this study. This finding can be supported by a previous study where the down-regulation of SERPINB11 with eupatilin 

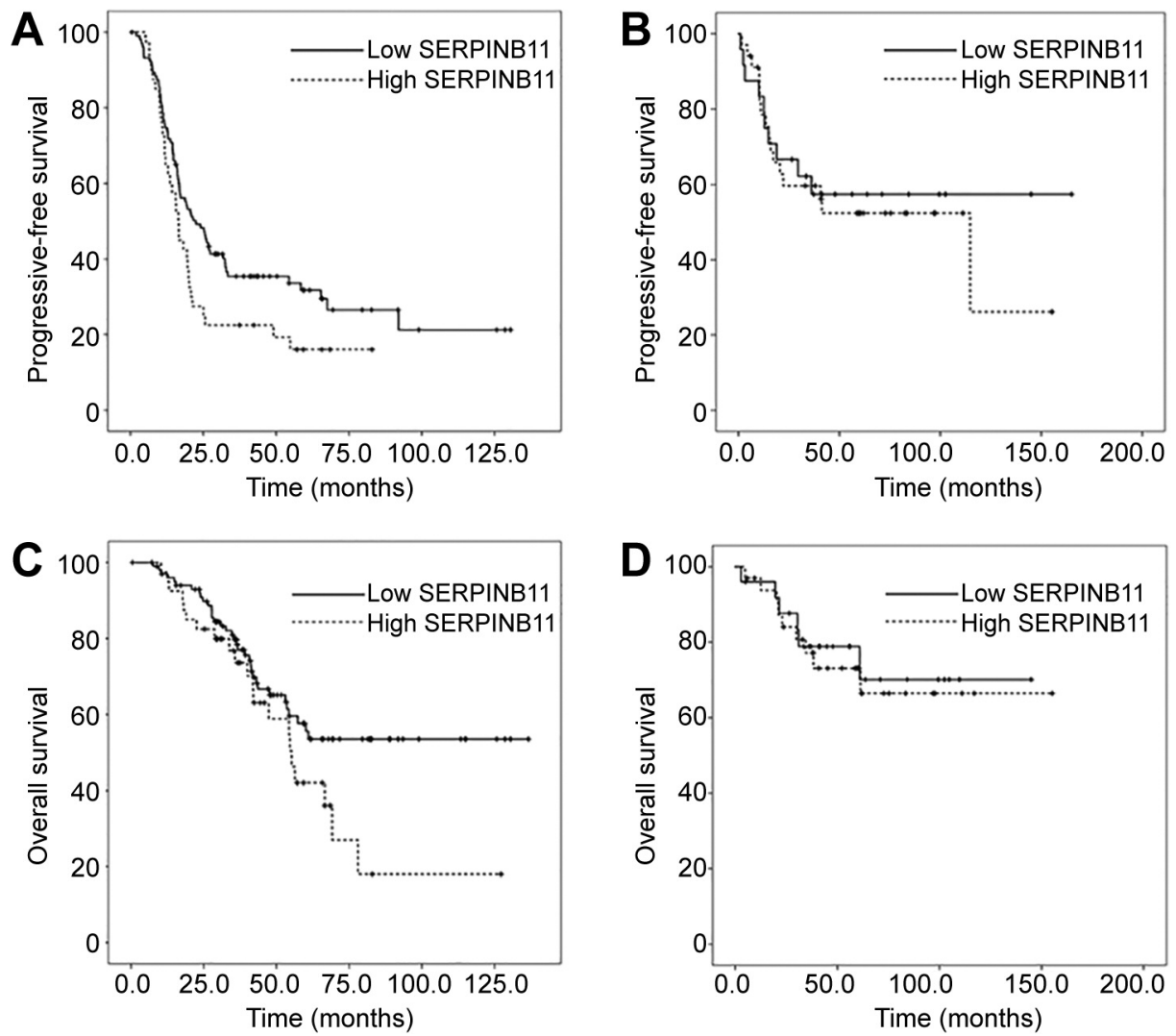

Figure 2. Comparison of progression-free survival and overall survival between low and high expression levels of SERPINB11 in patients with (A, $C)$ high-grade serous carcinoma and clear cell carcinoma of the ovary $(B, D)$.

Table II. Prognostic factors affecting survival in patients with high-grade serous carcinoma of the ovary.

\begin{tabular}{|c|c|c|c|c|c|c|}
\hline \multirow[b]{2}{*}{ Characteristics } & \multicolumn{2}{|c|}{ Univariate } & \multirow{2}{*}{$p$-Value } & \multicolumn{2}{|c|}{ Multivariate } & \multirow{2}{*}{$p$-Value } \\
\hline & HR & $95 \% \mathrm{CI}$ & & Adjusted HR & $95 \% \mathrm{CI}$ & \\
\hline \multicolumn{7}{|l|}{ Progression-free survival } \\
\hline Age $>52$ years & 1.122 & $0.762-1.652$ & 0.561 & 0.985 & $0.657-1.476$ & 0.940 \\
\hline FIGO stage III-IV & 4.091 & $1.295-12.923$ & 0.016 & 4.736 & $1.844-8.869$ & 0.033 \\
\hline Suboptimal cytoreduction & 2.238 & $1.511-3.316$ & $<0.001$ & 2.012 & $1.344-3.012$ & 0.001 \\
\hline No neoadjuvant chemotherapy & 1.367 & $0.787-2.372$ & 0.267 & 1.368 & $0.770-2.432$ & 0.285 \\
\hline High expression of SERPINB11 & 1.508 & $0.994-2.287$ & 0.054 & 1.505 & $0.982-2.306$ & 0.060 \\
\hline \multicolumn{7}{|l|}{ Overall survival } \\
\hline Age $>52$ years & 1.389 & $0.818-2.357$ & 0.224 & 1.280 & $0.748-2.190$ & 0.367 \\
\hline FIGO stage III-IV & 22.405 & $1.228-42.808$ & $<0.001$ & 19.803 & $1.654-38.802$ & $<0.001$ \\
\hline Suboptimal cytoreduction & 2.017 & $1.183-3.439$ & 0.010 & 1.776 & $1.039-3.037$ & 0.036 \\
\hline No neoadjuvant chemotherapy & 1.633 & $0.820-3.250$ & 0.163 & 1.488 & $0.734-3.015$ & 0.270 \\
\hline High expression of SERPINB11 & 1.605 & $0.933-2.761$ & 0.087 & 1.697 & $0.977-2.948$ & 0.060 \\
\hline
\end{tabular}

HR: Hazard ratio; CI: confidence interval; FIGO: International Federation of Gynecology and Obstetrics.

enhanced the effect of conventional chemotherapeutic agents against ovarian cancer cell progression (30). This means that the hormonal action of SERPINB11 can depend on the distribution of hormonal receptors in ovarian cancer tissues.
Previous studies have shown that $81 \%$ of the tumors of patients with HGSC were positive for estrogen receptors (13, 31 ), whereas CCC tissues and cell lines showed decreased or no expression of estrogen receptors (32-34). Especially, 
Table III. Prognostic factors affecting survival in patients with clear cell carcinoma of the ovary.

\begin{tabular}{|c|c|c|c|c|c|c|}
\hline \multirow[b]{2}{*}{ Characteristics } & \multicolumn{2}{|c|}{ Univariate } & \multirow{2}{*}{$p$-Value } & \multicolumn{2}{|c|}{ Multivariate } & \multirow{2}{*}{$p$-Value } \\
\hline & HR & $95 \% \mathrm{CI}$ & & Adjusted HR & $95 \% \mathrm{CI}$ & \\
\hline \multicolumn{7}{|l|}{ Progression-free survival } \\
\hline Age $>52$ y & 0.400 & $0.151-1.063$ & 0.066 & 0.157 & $0.046-0.539$ & 0.003 \\
\hline FIGO stage III-IV & 12.625 & $5.054-31.536$ & $<0.001$ & 10.272 & $3.482-30.302$ & $<0.001$ \\
\hline Suboptimal cytoreduction & 7.395 & $3.075-17.780$ & $<0.001$ & 4.619 & $1.432-14.894$ & 0.010 \\
\hline No neoadjuvant chemotherapy & 7.531 & $0.926-61.235$ & 0.059 & 4.447 & $0.430-45.950$ & 0.210 \\
\hline High-expression of SERPINB11 & 1.174 & $0.532-2.589$ & 0.691 & 0.844 & $0.350-2.032$ & 0.705 \\
\hline \multicolumn{7}{|l|}{ Overall survival } \\
\hline Age $>52$ y & 0.138 & $0.018-1.048$ & 0.056 & 0.052 & $0.034-3.286$ & 0.094 \\
\hline FIGO stage III-IV & 13.837 & $3.832-49.961$ & $<0.001$ & 9.084 & $2.299-35.887$ & 0.002 \\
\hline Suboptimal cytoreduction & 3.660 & $1.159-11.563$ & 0.027 & 1.717 & $0.375-7.875$ & 0.486 \\
\hline No neoadjuvant chemotherapy & 13.271 & $1.483-18.792$ & 0.021 & 10.892 & $0.893-21.302$ & 0.082 \\
\hline High-expression of SERPINB11 & 1.167 & $0.415-3.280$ & 0.769 & 1.073 & $0.330-3.482$ & 0.907 \\
\hline
\end{tabular}

HR, Hazard ratio; CI, confidence interval; FIGO, International Federation of Gynecology and Obstetrics.

$\mathrm{CCC}$ has been shown to have a high proportion of negative expression of estrogen and progesterone receptor $(81 \%$ and $92 \%$ ), and their expression levels have been reported not to affect survival of CCC patients (13).

To our best knowledge, this is the first study indicating that SERPINB11 may be a prognostic biomarker for patients with HGSC, suggesting that high expression of SERPINB11 might negatively affect survival of HGSC patients. However, this study has some limitations. We did not reveal the definite mechanism of how SERPINB11 can affect tumor progression in ovarian cancer, and the association between SERPINB11 expression and the distribution of hormonal receptors was not investigated. Thus, the potential of SERPINB11 as a biomarker should be further investigated in preclinical and clinical studies.

Conclusively, this study showed that high expression of SERPINBII was associated with poor prognosis, suggesting the potential of SERPINB11 as a prognostic biomarker in patients with HGSC.

\section{Conflicts of Interest}

All Authors declare no conflicts of interest in relation to this study.

\section{Authors' Contributions}

GS and HSK. designed this study. SJP, WL, SP, GS and HSK collected the data. SJP, WL, JM, HP, SP, HL, JK, EJL, GWY, NL, CL and HSK analyzed the results. SJP, WL, JWK, GS and HSK contributed to manuscript writing. All Authors read and approved the final manuscript.

\section{Acknowledgements}

This study was supported by grants from Seoul National University (No. 800-20180190; 800-20190437; 800-20200309; 800-20200458).

\section{References}

1 Torre LA, Trabert B, DeSantis CE, Miller KD, Samimi G, Runowicz CD, Gaudet MM, Jemal A and Siegel RL: Ovarian cancer statistics, 2018. CA Cancer J Clin 68(4): 284-296, 2018. PMID: 29809280. DOI: 10.3322/caac.21456

2 Labidi-Galy SI, Papp E, Hallberg D, Niknafs N, Adleff V, Noe M, Bhattacharya R, Novak M, Jones S, Phallen J, Hruban CA, Hirsch MS, Lin DI, Schwartz L, Maire CL, Tille JC, Bowden M, Ayhan A, Wood LD, Scharpf RB, Kurman R, Wang TL, Shih IM, Karchin R, Drapkin R and Velculescu VE: High grade serous ovarian carcinomas originate in the fallopian tube. Nat Commun 8(1): 1093, 2017. PMID: 29061967. DOI: 10.1038/ s41467-017-00962-1

3 Rojas V, Hirshfield KM, Ganesan S and Rodriguez-Rodriguez L: Molecular characterization of epithelial ovarian cancer: Implications for diagnosis and treatment. Int J Mol Sci 17(12): 2113, 2016. PMID: 27983698. DOI: 10.3390/ijms 17122113

4 Krag KJ, Canellos GP, Griffiths CT, Knapp RC, Parker LM, Welch WR, Klatt M and Andersen J: Predictive factors for longterm survival in patients with advanced ovarian cancer. Gynecol Oncol 34(1): 88-93, 1989. PMID: 2525510. DOI: 10.1016/00908258(89)90114-5

5 Goff BA, Sainz de la Cuesta R, Muntz HG, Fleischhacker D, Ek M, Rice LW, Nikrui N, Tamimi HK, Cain JM, Greer BE and Fuller AF Jr: Clear cell carcinoma of the ovary: a distinct histologic type with poor prognosis and resistance to platinumbased chemotherapy in stage III disease. Gynecol Oncol 60(3): 412-417, 1996. PMID: 8774649. DOI: 10.1006/gyno.1996. 0065

6 Itamochi $\mathrm{H}$, Kigawa $\mathrm{J}$ and Terakawa $\mathrm{N}$ : Mechanisms of chemoresistance and poor prognosis in ovarian clear cell carcinoma. Cancer Sci 99(4): 653-658, 2008. PMID: 18377417. DOI: $10.1111 / \mathrm{j} .1349-7006.2008 .00747 . \mathrm{x}$

7 Lee AW, Ness RB, Roman LD, Terry KL, Schildkraut JM, Chang-Claude J, Doherty JA, Menon U, Cramer DW, Gayther SA, Risch H, Gentry-Maharaj A, Goodman MT, Modugno F, Eilber U, Moysich KB, Berchuck A, Rossing MA, Jensen A, 
Wicklund KG, Cushing-Haugen KL, Hogdall E, Rudolph A Thompson PJ, Wilkens LR, Kjaer SK, Carney ME, Stram DO, Ramus SJ, Wu AH, Pike MC, Pearce CL and Ovarian Cancer Association Consortium: Association between menopausal estrogen-only therapy and ovarian carcinoma risk. Obstet Gynecol 127(5): 828-836, 2016. PMID: 27054934. DOI: 10.1097/AOG.0000000000001387

8 Trabert B, Brinton LA, Anderson GL, Pfeiffer RM, Falk RT, Strickler HD, Sliesoraitis S, Kuller LH, Gass ML, Fuhrman BJ, $\mathrm{Xu} \mathrm{X}$ and Wentzensen $\mathrm{N}$ : Circulating estrogens and postmenopausal ovarian cancer risk in the women's health initiative observational study. Cancer Epidemiol Biomarkers Prev 25(4): 648-656, 2016. PMID: 26908437. DOI: 10.1158/ 1055-9965.EPI-15-1272-T

9 Mungenast $\mathrm{F}$ and Thalhammer $\mathrm{T}$ : Estrogen biosynthesis and action in ovarian cancer. Front Endocrinol (Lausanne) 5: 192, 2014. PMID: 25429284. DOI: 10.3389/fendo.2014.00192

10 Ciucci A, Zannoni GF, Buttarelli M, Lisi L, Travaglia D, Martinelli E, Scambia G and Gallo D: Multiple direct and indirect mechanisms drive estrogen-induced tumor growth in high grade serous ovarian cancers. Oncotarget 7(7): 8155-8171, 2016. PMID: 26797759. DOI: 10.18632/oncotarget.6943

11 Kobayashi H, Kajiwara H, Kanayama S, Yamada Y, Furukawa N, Noguchi T, Haruta S, Yoshida S, Sakata M, Sado T and Oi $\mathrm{H}$ : Molecular pathogenesis of endometriosis-associated clear cell carcinoma of the ovary (review). Oncol Rep 22(2): 233-240, 2009. PMID: 19578761.

12 Munksgaard PS and Blaakaer J: The association between endometriosis and ovarian cancer: a review of histological, genetic and molecular alterations. Gynecol Oncol 124(1): 164-169, 2012. PMID: 22032835. DOI: 10.1016/j.ygyno.2011.10.001

13 Sieh W, Köbel M, Longacre TA, Bowtell DD, deFazio A, Goodman MT, Høgdall E, Deen S, Wentzensen N, Moysich KB, Brenton JD, Clarke BA, Menon U, Gilks CB, Kim A, Madore J, Fereday S, George J, Galletta L, Lurie G, Wilkens LR, Carney ME, Thompson PJ, Matsuno RK, Kjær SK, Jensen A, Høgdall C, Kalli KR, Fridley BL, Keeney GL, Vierkant RA, Cunningham JM, Brinton LA, Yang HP, Sherman ME, García-Closas M, Lissowska J, Odunsi K, Morrison C, Lele S, Bshara W, Sucheston L, Jimenez-Linan M, Driver K, Alsop J, Mack M, McGuire V, Rothstein JH, Rosen BP, Bernardini MQ, Mackay H, Oza A, Wozniak EL, Benjamin E, Gentry-Maharaj A, Gayther SA, Tinker AV, Prentice LM, Chow C, Anglesio MS, Johnatty SE, Chenevix-Trench G, Whittemore AS, Pharoah PD, Goode EL, Huntsman DG and Ramus SJ: Hormone-receptor expression and ovarian cancer survival: an Ovarian Tumor Tissue Analysis consortium study. Lancet Oncol 14(9): 853-862, 2013. PMID: 23845225. DOI: 10.1016/S1470-2045(13)70253-5

14 Law RH, Zhang Q, McGowan S, Buckle AM, Silverman GA, Wong W, Rosado CJ, Langendorf CG, Pike RN, Bird PI and Whisstock JC: An overview of the serpin superfamily. Genome Biol 7(5): 216, 2006. PMID: 16737556. DOI: 10.1186/gb-20067-5-216

15 Askew DJ, Cataltepe S, Kumar V, Edwards C, Pace SM, Howarth RN, Pak SC, Askew YS, Brömme D, Luke CJ, Whisstock JC and Silverman GA: SERPINB11 is a new noninhibitory intracellular serpin. Common single nucleotide polymorphisms in the scaffold impair conformational change. $\mathrm{J}$ Biol Chem 282(34): 24948-24960, 2007. PMID: 17562709. DOI: $10.1074 /$ jbc.M703182200
16 Lim W, Kim JH, Ahn SE, Jeong W, Kim J, Bazer FW, Han JY and Song G: Avian SERPINB11 gene: a marker for ovarian endometrioid cancer in chickens. Exp Biol Med (Maywood) 237(2): 150-159, 2012. PMID: 22289513. DOI: 10.1258/ebm. 2011.011250

17 Sanders MM and McKnight GS: Positive and negative regulatory elements control the steroid-responsive ovalbumin promoter. Biochemistry 27(17): 6550-6557, 1988. PMID: 3064812. DOI: $10.1021 / \mathrm{bi00417a053}$

18 Lim W, Kim JH, Ahn SE, Jeong W, Kim J, Bazer FW, Han JY and Song G: Avian SERPINB11 gene: characteristics, tissuespecific expression, and regulation of expression by estrogen. Biol Reprod 85(6): 1260-1268, 2011. PMID: 21849706. DOI: 10.1095/biolreprod.111.093526

19 Seo H, Park K, Lee H, Kim D, Song Y, Lim J, Song G and Han $\mathrm{J}$ : Physiological effects of diethylstilbestrol exposure on the development of the chicken oviduct. Journal of Animal Science and Technology 51(6): 485-492, 2015. DOI: 10.5187/JAST. 2009.51.6.485

20 Hasina R, Hulett K, Bicciato S, Di Bello C, Petruzzelli GJ and Lingen MW: Plasminogen activator inhibitor-2: a molecular biomarker for head and neck cancer progression. Cancer Res 63(3): 555-559, 2003. PMID: 12566295.

21 Yoshino H, Endo Y, Watanabe Y and Sasaki T: Significance of plasminogen activator inhibitor 2 as a prognostic marker in primary lung cancer: association of decreased plasminogen activator inhibitor 2 with lymph node metastasis. Br J Cancer 78(6): 833839, 1998. PMID: 9743310. DOI: 10.1038/bjc.1998.588

22 Foekens JA, Buessecker F, Peters HA, Krainick U, van Putten WL, Look MP, Klijn JG and Kramer MD: Plasminogen activator inhibitor-2: prognostic relevance in 1012 patients with primary breast cancer. Cancer Res 55(7): 1423-1427, 1995. PMID: 7882345.

23 Cataltepe S, Gornstein ER, Schick C, Kamachi Y, Chatson K, Fries J, Silverman GA and Upton MP: Co-expression of the squamous cell carcinoma antigens 1 and 2 in normal adult human tissues and squamous cell carcinomas. J Histochem Cytochem 48(1): 113-122, 2000. PMID: 10653592. DOI: $10.1177 / 002215540004800112$

24 Kato H: Squamous Cell Carcinoma Antigen. Serological Cancer Markers: 437-451, 2019. DOI: 10.1007/978-1-4612-0401-5_21

25 Solomon LA, Munkarah AR, Schimp VL, Arabi MH, Morris RT, Nassar H and Ali-Fehmi R: Maspin expression and localization impact on angiogenesis and prognosis in ovarian cancer. Gynecol Oncol 101(3): 385-389, 2006. PMID: 16443262. DOI: 10.1016/j.ygyno.2005.11.049

26 Gynecologic Oncology Group, Secord AA, Lee PS, Darcy KM, Havrilesky LJ, Grace LA, Marks JR and Berchuck A: Maspin expression in epithelial ovarian cancer and associations with poor prognosis: a Gynecologic Oncology Group study. Gynecol Oncol 101(3): 390-397, 2006. PMID: 16551475. DOI: 10.1016/j.ygyno.2006.02.014

27 Chou RH, Wen HC, Liang WG, Lin SC, Yuan HW, Wu CW and Chang WS: Suppression of the invasion and migration of cancer cells by SERPINB family genes and their derived peptides. Oncol Rep 27(1): 238-245, 2012. PMID: 21993616. DOI: 10.3892/or.2011.1497

28 Gettins PG: Serpin structure, mechanism, and function. Chem Rev 102(12): 4751-4804, 2002. PMID: 12475206. DOI: $10.1021 / \mathrm{cr} 010170+$ 
29 Pemberton PA, Stein PE, Pepys MB, Potter JM and Carrell RW: Hormone binding globulins undergo serpin conformational change in inflammation. Nature 336(6196): 257-258, 1988 PMID: 3143075. DOI: 10.1038/336257a0

30 Lee JY, Bae H, Yang C, Park S, Youn BS, Kim HS, Song G and Lim W: Eupatilin promotes cell death by calcium influx through ER-mitochondria axis with SERPINB11 inhibition in epithelial ovarian cancer. Cancers (Basel) 12(6): 1459, 2020. PMID: 32503295. DOI: $10.3390 /$ cancers 12061459

31 Voutsadakis IA: Hormone receptors in serous ovarian carcinoma: prognosis, pathogenesis, and treatment considerations. Clin Med Insights Oncol 10: 17-25, 2016. PMID: 27053923. DOI: 10.4137/CMO.S32813

32 Fujimura M, Hidaka T, Kataoka K, Yamakawa Y, Akada S, Teranishi A and Saito S: Absence of estrogen receptor-alpha expression in human ovarian clear cell adenocarcinoma compared with ovarian serous, endometrioid, and mucinous adenocarcinoma. Am J Surg Pathol 25(5): 667-672, 2001. PMID: 11342781. DOI: 10.1097/00000478-200105000-00016
33 Cameron RI, Ashe P, O'Rourke DM, Foster H and McCluggage WG: A panel of immunohistochemical stains assists in the distinction between ovarian and renal clear cell carcinoma. Int J Gynecol Pathol 22(3): 272-276, 2003. PMID: 12819395. DOI: 10.1097/01.PGP.0000071044.12278.43

34 Tanase Y, Yamada Y, Shigetomi H, Kajihara H, Oonogi A, Yoshizawa Y, Furukawa N, Haruta S, Yoshida S, Sado T, Oi H and Kobayashi H: Modulation of estrogenic action in clear cell carcinoma of the ovary (Review). Exp Ther Med 3(1): 18-24, 2012. PMID: 22969838. DOI: 10.3892/etm.2011.376

Received March 16, 2021

Revised May 31, 2021

Accepted June 1, 2021 